\title{
Factors affecting survival and long-term outcome in the cirrhotic patient undergoing hepatic resection for hepatocellular carcinoma
}

\author{
A. Chiappa*, A. P. Zbar $\uparrow$, R. A. Audisio $\neq$, B. E. Leoneף, F. Biella* \\ and C. Staudacher \\ *Department of General Surgery, University of Milan, European Institute of Oncology, Milan, Italy, \\ $\dagger$ St James's University Hospital, Leeds, UK, $₫$ Division of General Surgery, Whiston Hospital, Prescot, UK, \\ and $\Phi$ Department of Emergency Surgery and Department of Pathology, University of Milan, San Raffaele \\ Scientific Institute, Milan, Italy
}

\begin{abstract}
Aims: Prognostic analysis of hepatocellular carcinoma (HCC) in the cirrhotic patient undergoing hepatic resection is necessary in order to determine the clinical effect of hepatectomy on prognosis.

Patients and methods: Univariate and multivariate retrospective analyses were performed in 51 cirrhotic patients (38 men, 13 women; mean age 65 years, range 43-81 years) with supervening HCC undergoing hepatic resection between January 1993 and December 1997.

Results: Segmental liver resection was performed in 39 patients $(76 \%)$ with non-anatomical (wedge) resections in the remainder of cases. The post-operative mortality rate was $8 \%$. The tumours recurred in 23 patients $(45 \%)$, with 12 patients (52\% of recurrences) recurring within 1 year of surgery and 22 patients ( $96 \%$ of recurrences) within 3 years. Recurrent disease was most frequently intrahepatic (22 patients). Significant risk factors for recurrence were micro/ macro vascular invasion, and symptoms.

Conclusions: The recurrence rate of hepatocellular carcinoma in patients with cirrhosis undergoing surgical resection alone is high and actuarial survival at 4 years is low. Other approaches to the treatment of hepatocellular carcinoma in patients with cirrhosis require consideration.

(C) 2000 Harcourt Publishers Ltd
\end{abstract}

Key words: cirrhosis; hepatocellular carcinoma; hepatic resections; survival; disease-free survival; prognostic factors.

Introduction

The prevalence of cirrhosis in hepatocellular carcinoma (HCC) patients ranges from 60 to $90 \% .^{1}$ Frequent monitoring with ultrasonography (US) and $\alpha$-fetoprotein (AFP) levels have made it possible to discover small tumours $(\leq 2 \mathrm{~cm}$ in maximal diameter) in patients with cirrhosis and chronic viral hepatitis. ${ }^{2}$ Surgical resection with partial hepatic resection or liver transplantation are the only potentially curative treatments. ${ }^{3-6}$ However, hepatic resection can only be offered to patients with good liver function and well-defined, solitary tumours treatable with limited hepatic resection. Liver transplantation is the only option in patients with poor liver function or in nonresectable tumour(s), provided extrahepatic malignancy has been excluded.

The present study details experience in our institution gained in the surgical resection of HCC in patients with cirrhosis.

\footnotetext{
* Correspondence to: Antonio Chiappa, MD, Dept. of General Surgery, University of Milan, European Institute of Oncology, V. Ripamonti, 435, 21100, Milan, Italy.
}

Patients and methods

Fifty-one cirrhotic patients ( 38 men, 13 women; mean age 65 years, range 43-81 years) underwent hepatic resection for supervening $\mathrm{HCC}$ in the Department of Emergency Surgery at the University of Milan between January 1993 and December 1997. Their clinical features and demographic characteristics are summarized in Table 1.

Thirty-eight patients $(74 \%)$ were asymptomatic, with HCC being discovered by US during routine follow-up for cirrhosis. The remainder of cases $(26 \%)$ were symptomatic. Abdominal pain and upper gastrointestinal haemorrhage were the most frequently presenting symptoms. Nineteen patients $(37 \%)$ had hepatitis C virus, $11(21 \%)$ hepatitis C plus hepatitis B virus, $10(20 \%)$ isolated hepatitis B virus, eight $(16 \%)$ alcoholic cirrhosis and three $(6 \%)$ cryptogenic cirrhosis. Each case was classified according to the Child-Pugh criteria for hepatic functional reserve. ${ }^{7}$ All patients were also evaluated with indocyanine green retention $^{8}$ at $15 \mathrm{~min}$ as predictor of liver reserve. Thirtyeight patients $(74 \%)$ were in Child's group A, $12(24 \%)$ in Child's group B, and one (2\%) in Child's group C.

US before operation detected a single nodule in 31 patients $(61 \%)$, with a mean size of $5 \pm 4 \mathrm{~cm}$ in maximal diameter 
Table 1. Clinical and surgical features for the 51 cirrhotic patients with supervening $\mathrm{HCC}$ undergoing resection

\begin{tabular}{lr}
\hline Mean (SD) age (years) & $65(8)$ (range $43-81)$ \\
Sex (m:f) & $38: 13(2.9: 1)$ (ratio) \\
Aetiology & $19(37)$ \\
Post-necrotic HCV & $11(21)$ \\
Post-necrotic HBV and HCV & $10(20)$ \\
Post-necrotic HBV & $8(16)$ \\
Alcoholic & $3(6)$ \\
Other & \\
Child-Pugh classification & $38(74)$ \\
A & $12(24)$ \\
B & $1(2)$ \\
C & \\
HCC symptomatic & $13(26)$ \\
Yes & $38(74)$ \\
No & \\
AFP (ng/ml) & $19(37)$ \\
$<20$ ng/ml & $32(63)$ \\
$\geq 20$ ng/ml & \\
Types of hepatic resection & $19(37)$ \\
Segmentectomies & $11(22)$ \\
Bisegmentectomies & $12(23)$ \\
Non-segmental resections & $9(18)$ \\
Major hepatectomies &
\end{tabular}

Values in parentheses are percentages. SD, standard deviation; $\mathrm{HBV}$, hepatitis B virus; HCV, hepatitis C virus; AFP, $\alpha$-fetoprotein (normal value: $0-12 \mathrm{ng} / \mathrm{ml}$ ).

and two nodules of HCC in seven patients $(14 \%)$ with a mean size of $6 \pm 3 \mathrm{~cm}$. Abdominal computed tomography (CT) with intravenous contrast was performed in 45 patients $(88 \%)$ and showed one main tumour in 35 cases ( $78 \%$ ), two separate nodules in nine $(20 \%)$, and three nodules in one case $(2 \%)$. Satellite lesions, defined as a minute contrast enhancement near the primary lesion, were occasionally detected in 12 subjects $(26 \%)$.

Segmental resection was performed in 39 patients $(76 \%)$, while the remaining 12 patients $(24 \%)$ underwent nonanatomical (wedge) resection. Three patients $(6 \%)$ had repeat hepatic resections because of tumour recurrence in the hepatic remnant. Intra-operative ultrasonography (IOUS) was used in 31 patients $(61 \%)$. At operation the tumour could not be located by inspection or palpation in 12 patients $(24 \%)$ but was found by IOUS. This examination detected additional nodules in one patient who had been diagnosed as having a solitary tumour before surgery. Cirrhosis was histologically confirmed in all patients. Patients were staged according to the UICC TNM classification for HCC. ${ }^{9}$

Tumour differentiation was recorded according to the standard grading of Edmonson and Steiner. ${ }^{10}$ Thirty-nine patients had a clear surgical margins of more than $1 \mathrm{~cm}$, and 12 patients had a clear surgical margin of less than $1 \mathrm{~cm}$. There were no patients with hepatic resection margin involved.

All patients with HCC complicating their cirrhosis were resected for cure. The mean tumour size was $6 \pm 4 \mathrm{~cm}$ in maximal diameter (Table 2). According to the UICC TNM staging, seven patients $(14 \%)$ were stage $1,18(35 \%)$ stage $2,18(35 \%)$ stage $3 \mathrm{~A}$, and eight $(16 \%)$ stage $4 \mathrm{~A}$.

\section{Follow-up}

All cases were followed at 4-month intervals with serial AFP levels, US and CT scanning. Recurrence of $\mathrm{HCC}$ in
Table 2. Histopathological features of resected tumours in cirrhotic patients

\begin{tabular}{lr}
\hline Mean (SD) tumour size (cm) & $6(4)$ \\
$\leq 2 \mathrm{~cm}$ & $6(12)$ \\
$2-5 \mathrm{~cm}$ & $31(61)$ \\
$>5 \mathrm{~cm}$ & $14(27)$ \\
Number of tumours & \\
One tumour & $42(82)$ \\
$\quad$ More than one tumour & $9(18)$ \\
Satellite nodules & \\
$\quad$ Absent & $37(73)$ \\
Present & $14(27)$ \\
Capsule & \\
$\quad$ Present & $15(29)$ \\
Absent & $36(71)$ \\
Vascular invasion & $32(63)$ \\
Absent & $19(37)$ \\
Present & \\
Hepatic margin & 0 \\
Involved & $12(24)$ \\
Clear margin $(<1 \mathrm{~cm})$ & $39(76)$ \\
Clear margin $(\geq 1 \mathrm{~cm})$ &
\end{tabular}

Values in parentheses are percentages. SD, standard deviation.

relation to clinical and pathological characteristics of the tumour and type of cirrhosis was evaluated. The parameters used in the univariate analysis were as follows: sex, age, cirrhosis aetiology, presence or absence of alcoholism, hepatitis $\mathrm{C}$ virus, hepatitis B surface antigen, symptoms, AFP level, type of resection and hepatic resection margin (more or less than $1 \mathrm{~cm}$ ), tumour size and number, type of tumour, satellite nodules, tumour differentiation, tumour capsule, capsule invasion, vascular invasion, and presence of associated dysplasia.

\section{Analysis of the data}

Overall and disease-free survival analyses were conducted using the Kaplan-Meier method, ${ }^{11}$ with comparisons between groups performed by the log-rank test. ${ }^{12}$ Diseasefree survival was estimated from the date of the hepatic resection to the date of diagnosis of recurrent disease using US, CT scan, hepatic angiography or biopsy. Multivariate analysis using Cox's logistic regression technique ${ }^{13}$ was employed for variables found to be significant on univariate analysis. Statistical significance is recorded for $P$-values $<0.05$.

\section{Results}

There were four peri-operative deaths $(8 \%)$. Three patients died from hepatic failure and one from post-operative myocardial infarction. Post-operative ascites occurred in seven patients with progressive hepatorenal syndrome in one case. Major peri-operative complications occurred in $20 \%$ of cases including severe gastrointestinal bleeding in one, cardiopulmonary complications in three, significant but reversible hepatic failure in five, and abdominal wound dehiscence in one.

The mean hospital stay was 13 days (range 6-36 days). 


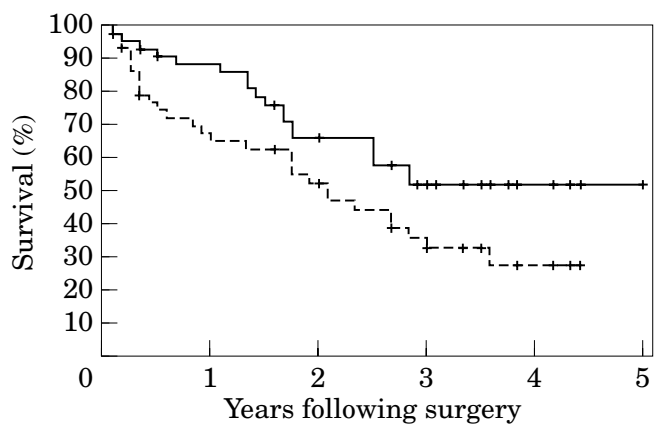

No. of patients at risk

$\begin{array}{lllllll}\text { Survival } & 47 & 37 & 25 & 17 & 6 & 1 \\ \text { DFS } & 47 & 28 & 20 & 11 & 3 & 0\end{array}$

Fig. 1. Overall (-) and disease-free (---) survival in 51 cirrhotic patients with hepatocellular carcinoma following resection.

Table 3. Recurrence of hepatocellular carcinoma for the 51 cirrhotic patients with supervening $\mathrm{HCC}$ undergoing resection

\begin{tabular}{lr}
\hline Incidence & 23 patients $(45 \%)$ \\
Site & \\
$\quad$ Liver & $19(83)$ \\
Liver/lung & $3(13)$ \\
Lung & $1(4)$ \\
Mean (SD) time of recurrence \\
(months) & $16(12)$ \\
Time to recurrence (months) & \\
$0-12$ & $12(52)$ \\
$13-24$ & $4(17)$ \\
More than 24 & $7(31)$
\end{tabular}

Values in parentheses are percentages. SD: standard deviation.

The mean follow-up was 28 months (range 4-60 months).

The 1-year, 3-year and 4-year overall and disease-free survival rates were 89,53 and $53 \%$, respectively, and 66,34 and $30 \%$, respectively (Fig. 1).

Recurrent HCC was diagnosed in 23 patients $(45 \%)$ with 12 patients ( $52 \%$ of recurrences) recurring within 1 year of surgery and 22 patients ( $96 \%$ of recurrences) within 3 years. Recurrent disease was most frequently detected in the liver parenchyma, usually as a solitary tumour near the resection margin.

Extrahepatic recurrences were detected in four cases $(17 \%)$, all presenting with solitary lung metastases (Table 3).

Tumour size did not affect either overall survival or disease-free survival. The 4-year overall survival rates for tumours $<2 \mathrm{~cm}, 2-5 \mathrm{~cm}$ and $>5 \mathrm{~cm}$ in maximal diameter were 50, 60 and 40\%, respectively. The 4-year disease-free survival rates for tumours $<2 \mathrm{~cm}, 2-5 \mathrm{~cm}$ and $>5 \mathrm{~cm}$ in maximal diameter were 17,36 and $27 \%$, respectively.

Histologic vascular invasion was found to be a relevant prognostic factor for overall and disease-free survival. The 1-year, 3-year and 4-year overall survival rates for patients with vascular invasion were 67,15 and $15 \%$, respectively,

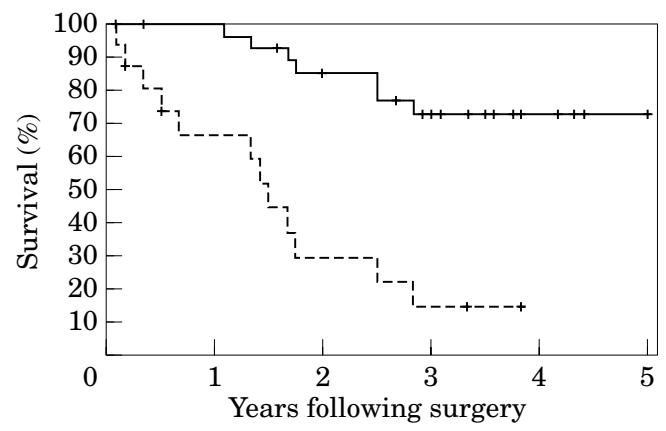

No. of patients at risk

$\begin{array}{lcccccc}\text { No. vasc. inv. } & 31 & 28 & 21 & 15 & 6 & 1 \\ \text { Vasc. inv. } & 16 & 9 & 4 & 2 & 0 & 0\end{array}$

Fig. 2. Overall survival for the 51 cirrhotic patients with supervening hepatocellular carcinoma undergoing resection: the effect of microvascular invasion. (No vascular invasion [-] vs vascular invasion $[---]: P<0.0001$.)

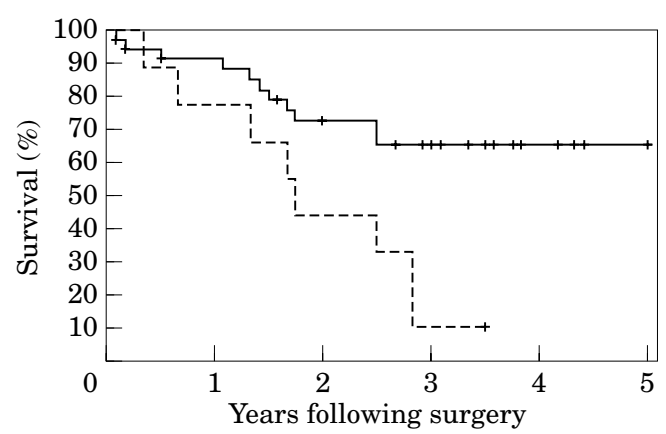

No. of patients at risk

$\begin{array}{lcccccc}\text { Solitary } & 39 & 30 & 21 & 16 & 6 & 1 \\ \text { Multiple } & 8 & 7 & 4 & 1 & 0 & 0\end{array}$

Fig. 3. Overall survival for the 51 cirrhotic patients with supervening hepatocellular carcinoma undergoing resection. (Solitary $[-]$ vs multiple $[---]$ tumours: $P<0.01$.)

and 100, 73 and $73 \%$, respectively, in those cases without vascular invasion $(P<0.0001)$ (Fig. 2$)$.

The 1-year, 3-year and 4-year disease-free survival rates for patients with vascular invasion were 40, 13 and 13\%, respectively, and 79,46 and $38 \%$, respectively, in those cases without vascular invasion $(P<0.005)$

Four patients with microscopic vascular invasion developed recurrence within 1 year following surgery and three-quarters of those with microvascular invasion (12 patients) died within 3 years of hepatectomy.

The 1-year, 3-year and 4-year overall survival rates for patients with a solitary tumour were 92, 66 and $66 \%$, respectively, whereas equivalent survival rates for patients with more than one tumour were 78,11 and $11 \%$, respectively $(P<0.01)$ (Fig. 3).

The 1-year, 3-year and 4-year disease-free survival rates for patients with a solitary tumour were 71,41 and $35 \%$, 


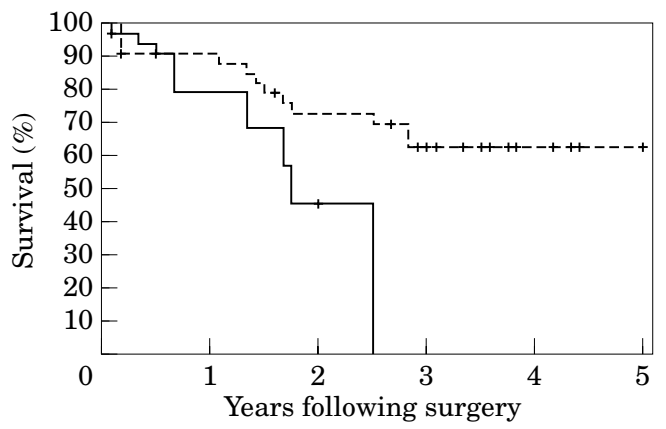

No. of patients at risk

$\begin{array}{lcccccc}\text { Asymptomatic } & 37 & 30 & 23 & 17 & 6 & 1 \\ \text { Symptomatic } & 10 & 7 & 2 & 0 & 0 & 0\end{array}$

Fig. 4. Overall survival for the 51 cirrhotic patients with supervening hepatocellular carcinoma undergoing resection. (Symptomatic [vs asymptomatic $[---]$ patients: $P<0.05$.)

Table 4. Multivariate analysis of prognostic variables affecting overall survival and disease-free survival in 51 cirrhotic patients following hepatic resection for hepatocellular carcinoma

\begin{tabular}{lccccc}
\hline Variables & $\mathrm{R}$ & $\mathrm{SE}$ & $P$ & $\mathrm{RR}$ & $\mathrm{IC}$ \\
\hline Microvascular invasion & & & & & \\
$\quad$ Overall survival & 0.3043 & 0.4849 & 0.0002 & 6.2 & $2.4-16.1$ \\
$\quad \begin{array}{c}\text { Disease-free survival } \\
\text { Multiple tumour }\end{array}$ & 0.1728 & 0.3876 & 0.0062 & 2.9 & $1.4-6.2$ \\
$\quad \begin{array}{c}\text { Overall survival } \\
\quad \text { Disease-free survival }\end{array}$ & 0.1832 & 0.4708 & 0.0113 & 3.3 & $1.3-8.3$ \\
$\begin{array}{c}\text { Symptomatic tumour } \\
\quad \text { Overall survival }\end{array}$ & 0.1282 & 0.5147 & 0.0413 & 2.9 & $1.1-7.8$ \\
$\quad$ Disease-free survival & 0.1073 & 0.4542 & 0.0423 & 2.5 & $1.1-6.1$ \\
\hline
\end{tabular}

$\mathrm{R}$, regression coefficient; SE, standard error; RR, relative risk; IC, confidence interval.

respectively, compared with 44,11 and $11 \%$, respectively, for patients presenting with multiple tumours $(P<0.05)$.

The 1-year, 3-year and 4-year overall survival rates for patients with a symptomatic tumour were 80,0 and $0 \%$, respectively, whereas equivalent survival for patients with an asymptomatic tumour were 91,63 and $63 \%$, respectively $(P<0.05)$ (Fig. 4).

The 1-year, 3-year and 4-year disease-free survival rates for patients with a symptomatic tumour were 40,0 and $0 \%$, compared with 73, 41 and $35 \%$, respectively, for patients with an asymptomatic tumour $(P<0.05)$.

To clarify the significance of each significant parameter by univariate analysis, multiple logistic regression analysis was carried out with Cox's proportional hazard model.

Table 4 shows the result of multivariate analysis assessing vascular invasion, multiple tumour and symptomatic tumour.

The type of cirrhosis, presence or absence of a tumour capsule, surgical resection margin or tumour grading did not affect either overall survival or disease-free survival on univariate analysis.

\section{Discussion and conclusions}

Strict follow-up of patients with cirrhosis, mainly by US examination, has increased the frequency of diagnosis of small resectable HCC. ${ }^{2,4}$ This is reflected in this series by the fact that $74 \%$ of patients were asymptomatic and detected on routine follow-up US. Hepatectomy appears to be relatively safe even in cirrhotic patients with supervening HCC with an overall mortality of $8 \%$ in our series. Moreover, the 5year survival in such patients is between 33 and $46 \%$ in most Western countries ${ }^{1,14,15}$ and 25 and $33 \%$ in reported Asian series. ${ }^{16-18}$

Intra-operative ultrasonography is a valuable tool not only for detecting the tumour, but also for establishing adequate resection margins sparing as much parenchyma as possible. ${ }^{19-22}$ In this study, $24 \%$ of tumours were not found on careful inspection or palpation of the cirrhotic liver but were only located with IOUS examination.

The introduction of limited hepatectomy using IOUS ${ }^{23,24}$ has an acceptable morbidity in cirrhosis complicated by supervening $\mathrm{HCC}^{25-27}$ There has been considerable improvement in the prediction of the safety of liver resection in selected patients with cirrhosis and impaired hepatic reserve; ${ }^{28,29}$ however, tumour recurrence during follow-up in this group is common. ${ }^{17,23,30}$ The recurrence rate in this series was $49 \%$ in patients surviving surgery, and was similar to that of other series. ${ }^{3,18,31,32}$ The cumulative recurrence rate at 3 years was $57 \%$ in our study and was similar to that reported by Belghiti et $a l .{ }^{33}$ who found an overall intrahepatic recurrence of $60 \%$, with a cumulative intrahepatic recurrence rate of $81 \%$ at 3 years depending on the size of the original primary, the presence of a tumour capsule and the pre-operative AFP level.

The majority of tumour recurrences in our study were intrahepatic and occurred within the first year after resection, as reported by other authors. ${ }^{18,34}$ Most presented as solitary nodules close to the original resection line. This has been a similar finding in other studies concerning cirrhotics with supervening $\mathrm{HCC}^{35,36}$ as well as in $\mathrm{HCC}$ patients without cirrhosis, ${ }^{37}$ where intrahepatic recurrence most commonly follows small non-anatomical resections.

The most significant prognostic factors reported for recurrence have included: more than one primary tumour, tumour size greater than $2 \mathrm{~cm}$ in maximal diameter, the presence of a tumour capsule, and vascular invasion. ${ }^{3,30,38-42}$ In the present series of cirrhotic subjects, tumour size was not a significant prognostic factor and the presence of tumour encapsulation did not reach significance. Vascular invasion and symptomatic tumours were significant prognostic factors in multivariate analysis, which correlated with recurrence. This highlights the importance of close follow-up in patients with cirrhosis in order to detect asymptomatic tumours.

If tumour recurrence occurs, there are several treatment options ${ }^{43}$ depending on several parameters such as size and location of the tumour, number of tumour nodules and functional hepatic reserve. One option is to repeat the hepatic resection and survival in these cases has been as high as $75 \%$ at 3 years. ${ }^{32}$ Ringe et al..$^{44}$ have found a high incidence of HCC recurrence with re-resection, and they have proposed liver transplantation in cases of resectable 
tumour recurrence; achieving better results with this technique. Tumour recurrences may also be treated by chemoembolization, ${ }^{3,31,41}$ or intra-tumoural alcohol injection. ${ }^{41}$ When no treatment is possible, the mean survival is only as long as 2 months. ${ }^{5}$

Hepatic transplantation is considered the best therapeutical option for patients with small hepatocellular carcinoma complicating liver cirrhosis, though the limited organ availability, and its high costs conflict with the popularization of this procedure. ${ }^{3,40,45}$

The poor results obtained with resection of HCC in cirrhotics in terms of tumour recurrence and patient survival invite reconsideration of the best treatment options for the cirrhotic patient with supervening $\mathrm{HCC}$ and good functional reserve.

\section{References}

1. Thompson H, Tompkins RK, Longmire WB. Major hepatic resection. A 25-year experience. Ann Surg 1983; 197: 247-53.

2. Maringhini A, Cottone M, Sciarrino E, Marceno MP, La Seta F, Fusco G, Rinaldi F, Pagliaro L. Ultrasonography and alpha-fetoprotein in diagnosis of hepatocellular carcinoma in cirrhosis. Dig Dis Sci 1988; 33: 47-51.

3. Iwatzuki S, Starzl TE, Sheahan DG, Yokoyama I, Demetris AJ, Todo S, Tzakis AG, Van Thiel DH, Carr B, Selby R, Madariaga J. Hepatic resection versus transplantation for hepatocellular carcinoma. Ann Surg 1991; 214: 221-9.

4. Nagasue N, Yukaya H, Ogawa Y, Sasaki Y, Chang Y-C, Niimi K. Clinical experience with 118 hepatic resections for hepatocellular carcinoma. Surgery 1986; 99: 694-701.

5. Okuda K, Ohtsuki T, Obata H, Tomimatsu M, Okazaki N, Hasegawa H, Nakajima Y, Ohnishi K. Natural history of hepatocellular carcinoma and prognosis in relation to treatment. Study of 850 patients. Cancer $1985 ; \mathbf{5 6}$ : 918-28.

6. Schwartz ME. Primary hepatocellular carcinoma: transplant versus resection. Semin Liver Dis 1994; 14: 135-9.

7. Pugh RNH, Murray-Lyon IM, Danson JL, Pietroni MC, Williams R. Transsection of esophagus for bleeding varices. $\mathrm{Br}$ J Surg 1973; 60: 646-50.

8. Kawasaki S, Sugiyama Y, Iga T, Hanano M, Sanjo K, Beppu T, Idezuki Y. Pharmacokinetic study on the hepatic uptake of indocyanine green in cirrhotic patients. Am J Gastroenterol 1985; 80: 801-6.

9. Sobin LH, Wittekind Ch (eds). TNM Classification of Malignant Tumours. 4th edn. New York: Wiley-Liss, Inc., 1997.

10. Edmonson HA, Steiner PE. Primary carcinoma of the liver: a study of 100 cases among 48900 necropsies. Cancer 1954; 7: 462-503.

11. Kaplan GL, Meier P. Nonparametric estimation from incomplete observation. J Am Stat Assoc 1958; 53: 457-81

12. Peto R, Pike MC. Conservation of the approximation (o-E2)/ $\mathrm{E}$ in the log-rank test for survival data on tumour incidence data. Biometrics 1973; 29: 579-84.

13. Cox DR. Regression models and life tables. JR Stat Soc Ser B 1972; 34: 187-220.

14. Iwatzuki S, Shaw BW, Starzl TE. Experience with 150 liver resections. Ann Surg 1983; 197: 247-53.

15. Sesto ME, Vogt DP, Hermann RE. Hepatic resection in 128 patients: a 24-year experience. Surgery 1987; 102: 846-51.

16. Chen MF, Hwang TL, Jeng LBB, Jan YY, Wang CS, Chou FF. Hepatic resection in 120 patients with hepatocellular carcinoma. Arch Surg 1989; 124: 1025-8.

17. Nagao $T$, Goto $S$, Kawano $N$, Inoue $S$, Mizuta $T$, Morioka Y, Omori Y. Hepatic resection for hepatocellular carcinoma: clinical features and long-term prognosis. Ann Surg 1987; 205: $33-40$.

18. Suenaga M, Nakao A, Harada A, Nonami T, Okada Y, Sugiura
H, Uehara S, Takagi H. Hepatic resection for hepatocellular carcinoma. World J Surg 1992; 16: 97-105.

19. Bismuth H, Castaing D, Garden OJ. The use of operative ultrasound in surgery of primary liver tumours. World J Surg 1987; 11: 610-14.

20. Gozzetti G, Mazziotti A, Bolondi L, Cavallari A, Grigioni W, Casanova P, Bellusci R, Villanacci V, Labo G. Intraoperative ultrasonography in surgery for liver tumours. Surgery 1986; 90: $523-30$.

21. Makuuchi M, Hasegawa H, Yamazaki S, Takayasu K, Moriyama N. The use of operative ultrasound as an aid to liver resection in patients with hepatocellular carcinoma. World J Surg 1987; 11: 615-21.

22. Nagasue N, Konho H, Chang YC, Galizia G, Hayashi T, Yukaya $\mathrm{H}$, Nakamura $\mathrm{T}$. Intraoperative ultrasonography in resection of small hepatocellular carcinoma associated with cirrhosis. Am J Surg 1989; 158: 40-2.

23. Kanematsu T, Takenaka K, Matsumata T, Furuta T, Sigimachi $\mathrm{K}$, Inokuchi K. Limited hepatic resection effective for selected cirrhotic patients with primary liver cancer. Ann Surg 1984; 199: 51-6.

24. Sheu JC, Lee CS, Sung JL, Chen DS, Yong PM, Lin TY Intraoperative hepatic ultrasonography: an indispensable procedure in resection of small hepatocellular carcinomas. Surgery 1985; 97: 97-103.

25. Fuster J, Garcia-Valdecasas JC, Grande L, Tabet J, Bruix J, Anglada T, Tania P, Lacy AM, Gonzales X, Vilana R, Bru C, Sole M, Visa J. Hepatocellular carcinoma and cirrhosis: results of surgical treatment in a European series. Ann Surg 1996; 223: 297-302.

26. Launois B, Chauvin J, Machado MC, Bourdonne P, Campion JP, Bardaxoglou E. Surgical treatment of hepatocarcinoma in cirrhosis. Ann Gastroenterol-Hepatol-Paris 1996; 32: 35-40.

27. Sheen PC, Lee KT, Chen HY, Ker CG. Conservative hepatic resection for hepatocellular carcinoma of cirrhotic patients. Int J Surg 1996; 81: 280-3.

28. Okamoto E, Kyo A, Yamanaka N, Tanaka N, Kuwata K. Prediction of the safe limits of hepatectomy by combined volumetric and functional measurements in patients with impaired hepatic function. Surgery 1984; 95: 586-92.

29. Ozawa K, Yamaoka Y, Kitamura O, Nambu H, Hamiyama Y. Clinical application of cytochrome a $(+a 3)$ assay of mitochondria from liver specimens: an aid in determining metabolic tolerance of liver remnant for hepatic resection. Ann Surg 1974; 180: 868-76.

30. Kanematsu T, Matsumata T, Takenaka K, Yoshida Y, Higashi $\mathrm{H}$, Sugimachi K. Clinical management of recurrent hepatocellular carcinoma after primary resection. $\mathrm{Br} J$ Surg 1988; 75: 203-6.

31. Sasaki $Y$, Imaoka $S$, Masutani $S$, Ohashi I, Ishikawa $O$, Koyama $\mathrm{H}$, Iwanaga $\mathrm{T}$. Influence of coexisting cirrhosis on long-term prognosis after surgery in patients with hepatocellular carcinoma. Surgery 1992; 112: 515-21.

32. Shirabe K, Kanematsu T, Matsumata T, Adachi E, Akazawa $\mathrm{K}$, Sugimachi K. Factors linked to early recurrence of small hepatocellular carcinoma after hepatectomy: univariate and multivariate analyses. Hepatology 1991; 14: 802-5.

33. Belghiti J, Panis Y, Farges O, Benhamou JP, Fekete F. Intrahepatic recurrence after resection of hepatocellular carcinoma complicating cirrhosis. Ann Surg 1991; 214: 114-17.

34. Sasaki Y, Imaoka S, Fujita M, Miyashi Y, Ohigashi H, Ishikawa O, Furukawa H, Koyama H, Iwanoga T, Kasugai H. Regional therapy in the management of intrahepatic recurrence after surgery for hepatoma. Ann Surg 1987; 206: 40-7.

35. Bismuth H, Chiche L, Adam R, Castaing D, Diamond T, Dennison A. Liver resection versus transplantation for hepatocellular carcinoma in cirrhotic patients. Ann Surg 1993; 218: $145-51$

36. Kawasaki S, Makuuchi M, Miyagawa S, Kakazu T, Hayashi K, Kasai H, Miwa S, Hiu A, Mnishimaki K. Results of hepatic resection for hepatocellular carcinoma. World J Surg 1995; 19: $31-4$.

37. Bismuth H, Chiche L, Castaing D. Surgical treatment of 
hepatocellular carcinomas in noncirrhotic liver: experience with 68 resections. World J Surg 1995; 19: 35-41.

38. Adachi E, Maeda T, Kajiyama K, Kinukawa N, Matsumata T, Sugimachi K, Tsuneyoshi M. Factors correlated with portal venous invasion by hepatocellular carcinoma. Cancer 1996; 77: 2022-31.

39. Hsu H-C, Sheu JC, Lin YH, Chen DS, Lee CS, Hwang LY, Beasley P. Prognostic histologic features of resected small hepatocellular carcinoma (HCC) in Taiwan. A comparison with resected large HCC. Cancer 1985; 56: 672-80.

40. Kawano N, Ohmori Y, Inoue O, Nagao S, Moroka Y. Longterm prognosis of surgical patients with hepatocellular carcinoma. Cancer Chemother Pharmacol 1989; 23 (Suppl.): S129.

41. Liver Cancer Study Group of Japan. Primary liver cancer in Japan: clinicopathologic features and results of surgical treatment. Ann Surg 1990; 211: 277-87.
42. Thai BL. Les facteurs de prognostic de l'hépatocarcinome. $J$ Chir (Paris) 1989; 126: 405-12.

43. Matsuda Y, Ito T, Oguchi Y, Nakajima K, Izukura T. Rationale of surgical management for recurrent hepatocellular carcinoma. Ann Surg 1993; 217: 28-34.

44. Ringe B, Pichlmayr R, Wittekind C, Tusch G. Surgical treatment of hepatocellular carcinoma: experience with liver resection and transplantation in 198 patients. World J Surg 1991; 15: 270-85.

45. Gugenheim J, Baldini E, Casaccia M, Ouzan D, Saint-Paul MC, Mouiel J. Hepatic resection and transplantation for hepatocellular carcinoma in patients with cirrhosis. Gastroenterol Clin Biol 1997; 21: 590-5.

Accepted for publication 30 September 1999 